This document is the accepted manuscript version of the following article: Casado-Martinez, M. del C., Wildi, M., Ferrari, B. J. D., \& Werner, I. (2018). Prioritization of substances for national ambient monitoring of sediment in Switzerland. Environmental Science and Pollution Research, 25(4), 3127-3138. https://doi .org/10.1007/s11356-017-9082-6

\title{
PRIORITIZATION OF SUBSTANCES FOR NATIONAL AMBIENT MONITORING OF SEDIMENT IN SWITZERLAND
}

Maria del Carmen Casado-Martinez, Michel Wildi, Benoit J.D. Ferrari

Swiss Centre for Applied Ecotoxicology Eawag/EPFL. Station 2 (GR B0 391), 1015 Lausanne, Switzerland.

Inge Werner

Swiss Centre for Applied Ecotoxicology Eawag/EPFL. Überlandstrasse 133, 8600 Dübendorf, Switzerland

\section{Corresponding Author:}

Maria del Carmen Casado-Martinez

Tel.: +41(0)216930896

Fax: +41(0)216938035

E-mail address: carmen.casado@centreecotox.ch

Abstract: In Switzerland, surface waters are protected by the Swiss Water Protection Ordinance (OEaux; OFEV 1998), which stipulates that the water quality shall be such that: the water, suspended matter and sediments contain no persistent synthetic substances to ensure the protection of aquatic life. Local agencies are in charge of water quality monitoring, using a set of validated methods. Several lists of priority substances have been developed for aquatic microcontaminants for surface water monitoring but not for sediments. Some local agencies have established sediment monitoring programs, but to date, there exists no harmonized methodology for sediment quality assessment in Switzerland.

Within the main goal of developing and providing methodologies for monitoring sediment quality in Switzerland, a screening was performed to help prioritize sediment-relevant microcontaminants. The screening approach was largely based on the NORMAN (network of reference laboratories, research centres and related organisations for monitoring emerging environmental substances) system and 
was carried out in four steps: 1) identification of candidate substances; 2) selection of sediment relevant substances; 3) classification of substances into different categories based on identified data gaps and envisaged actions; 4) ranking within each action category. This paper describes the methodology used in the prioritization process for sediment-relevant substances and provides recommendations for monitoring strategies in Switzerland.

Keywords substance prioritization, sediment, monitoring, risk-based assessment, 


\section{Introduction}

In Switzerland, surface waters are protected by the Swiss Water Protection Ordinance (OEaux; OFEV 1998), which stipulates that the water quality shall be such that water, suspended matter and sediments contain no persistent synthetic substances to ensure the protection of aquatic life. The so called Modular Stepwise Procedure (MSP) provides the framework for the standardized investigation of the hydrology, ecomorphology, biology, chemistry and ecotoxicology of surface waters. Local agencies are in charge of water quality monitoring, using a set of validated methods ("modules") that varies according to the scale and goals of their respective monitoring strategies. Regarding the particulate phases (bed sediments, suspended sediments) of aquatic environments, some local agencies already have monitoring programs in place, but there is currently no harmonized methodology for sediment quality assessment in Switzerland. According to a situation analysis performed in 2012, current sediment quality assessment in Switzerland mainly consists of physicochemical analyses, with metals and to a lesser extent polycyclic aromatic hydrocarbons and polychlorinated biphenyls being most commonly quantified (Flück et al. 2012). Sediments, however, may accumulate a large number of substances including, e.g. pesticides, insecticides, pharmaceuticals and veterinary products, and industrial chemicals that are released to surface water bodies from numerous point and non-point sources. A number of these substances have been prioritized for surface water monitoring (Götz et al. 2010, Wittmer et al. 2014). However, these prioritization exercises have targeted water-phase chemicals only, while recognizing the need for "a completely different assessment and monitoring strategy for substances likely to be bound to suspended particles".

Within the Water Framework Directive (WFD), the introduction of sediments and biota as analytical matrix for chemical monitoring has the objective to assess the long-term impacts of anthropogenic activities and to ensure that the existing levels of contamination do not increase to a stage that pose 
a threat to the environment and human health (EC 2010). Sediments offer numerous advantages for trend monitoring because the changes in pollution in this environmental compartment are not as fast as in the water column and reliable long-term comparisons can be carried out. While bottom sediments are the recommended matrix for monitoring certain metals and some hydrophobic compounds in marine and lentic water bodies (EC 2012, Maggi et al. 2012), the preferred matrix in lotic and dynamic water bodies is suspended particulate matter due to high variability in the substrate matrix (EC 2010). For the preparation of a MSP module for sediment quality assessment in Switzerland, a situation analysis was performed and a screening system was implemented for the identification and ranking of substances relevant to particulate matter and sediment monitoring. Here we describe the methodology used, which is based on the NORMAN approach, to deal with considerable data gaps for this environmental compartment. Substances were classified in categories, each with specific recommendations for monitoring and data acquisition according to available exposure and effect data. Within each category, substances were ranked according to several exposure, hazard and risk scores.

\section{Material and methods}

\subsection{The prioritization approach}

Chemical substances are most commonly assessed and prioritized according to a four-step screening system (Bu et al. 2013) summarized as follows: 1) the set-up of a chemical "universe", which consists of a database of substances with entries from different origins such as registered chemicals for a certain use, contaminants measured in the studied site, etc.; 2) the selection of parameters related to exposure and hazard, such as measured environmental concentrations, consumption data, toxicity, etc.; 3) an algorithm for organizing, weighting, and aggregating parameters; and 4) the set-up of the priority list, which helps managers and/or researchers to take actions. Such screening systems rely heavily on monitoring data and the evaluation of the risk posed by the measured concentrations in 
the environment (e.g. Slobodnik et al. 2012). In Switzerland, this approach works well for the water compartment or legacy pollutants in terms of data availability, but relevant data for the sediment compartment for compounds other than metals, PAHs and PCBs is scarce. In such cases, the production or use volume are most commonly used as exposure indicators (Daginnus et al. 201; Karahan-Ozgun et al. 2017).

Accounting for important gaps of knowledge for a large number of emerging substances, the NORMAN network (Network of reference laboratories, research centres and related organisations for monitoring emerging environmental substances) proposed a prioritization system that first classifies substances into categories according to recommended actions for monitoring and/or research (Dulio and Von der Ohe 2012). For example, one category comprises substances with scarce monitoring data, another contains substances with no effect data, and so on. The substances are then scored and ranked within categories. Such generic prioritization systems can be tailored to the purpose and application of the resulting list. For example, if the objective is to rank chemicals within a particular type according to their environmental risk, relevant effect endpoints and receptors to be protected are chosen (Besse and Garric 2008; Homem et al. 2014; Di Nica et al. 2015; Donnachie et al. 2015; AlKhazrajy and Boxall 2016; Guo et al. 2016, Tsaboula et al. 2016). If the objective is to rank contaminants for environmental monitoring at the national or regional level, exposure indicators are selected at the proper spatial scale. In the European Union (EU) several prioritization exercises were carried out for the establishment of the WFD priority substance list (James et al. 2009; Daginnus et al. 2011). This priority list is complemented by River Basin Specific Pollutants (RBSP) identified by individual EU Member States or commissions (Von der Ohe et al. 2011; Slobodnik et al. 2012, Smital et al. 2013, Tsaboula et al. 2016).

Here the prioritization of sediment relevant substances was carried out in four steps (Fig 1): 
- Step 1: Identification of candidate substances.

- Step 2: Selection of sediment relevant substances.

- Step 3: Classification into action categories.

- Step 4: Ranking within each action category.

\subsubsection{Step 1: Candidate list}

The list of candidate substances should virtually include all substances of potential concern. For this exercise, we included plant protection products and biocides authorized in Switzerland (Wittmer et al. 2014), compounds detected in urban waste water effluents (Götz et al. 2010), substances most commonly analyzed in sediments by Swiss cantonal agencies, and substances listed in the Swiss Contaminated Sites Ordinance (CSO) and the Swiss Pollutant Release and Transfer Register (SwissPRTR). We also included the WFD priority as well as watch list compounds and substances detected in sediments during previous monitoring campaigns. An initial list of 1089 entries was obtained. This list does not include the universe of authorized and non-authorized substances that are not yet covered by regulation nor monitoring campaigns. A first screening was completed by deleting entries where the chemical identity or the compound was not clearly identified.

Substances were divided into two groups: metals and organic substances. Metals were screened separately and therefore excluded from this exercise. Organic substances were grouped into 11 categories: organochlorine pesticides, insecticides, biocides, herbicides, fungicides, pharmaceuticals and hormones, PCBs, PAHs, brominated flame retardants, perfluorosulfonic acids and related compounds, and a large category named "other substances", which included phthalates, other plasticizers and synthetic musks among others. This categorization of substances was performed 
mainly for practical purposes and cannot be considered precise because many substances have multiple uses.

2.1.2. Step 2: Identification of sediment relevant substances

A substance was considered relevant for the sediment compartment if one of the following criteria were met:

- Proven occurrence of the substance in the sediment compartment: the substance has been measured in sediments in Switzerland or elsewhere. Measured environmental concentrations of organic micro-pollutants in Swiss sediments were obtained from the scientific literature, grey literature, specific campaigns implemented at Lake Geneva and other studies carried out in Swiss lakes. In the absence of data for Swiss sediments, publicly available monitoring data from other countries were taken into account, focusing on monitoring programs in neighbor countries. The full list of data sources is presented as Supplementary Information.

- Regulatory environmental quality standards (EQS) for sediments and threshold effect concentrations (TECs) exist elsewhere. We obtained existing EQS from regulatory agencies in EU member states and complemented them with TECs derived using empirical correlations between chemical concentrations in sediments and biological effects in the USA (MacDonald et al. 2000) and Flanders, Belgium (de Deckere et al. 2011). Additional threshold values, which were used for risk assessment purposes but not for assessing the relevance of a given substance for the sediment compartment, were obtained from predicted no effect concentrations (PNECs) from REACH dossiers, or calculated from chronic 28-day NOEC values for sediment-dwelling organisms according to methods recommended by the EU technical guidance document (TGD) for the development of EQS (EC 2011). For risk assessment we also derived sediment EQS from chronic EQS for surface waters (mainly those developed by the Swiss Centre for Applied 
Ecotoxicology) using the equilibrium-partitioning approach (EqP, see supplementary information). The EqP is an accepted method for non-ionic chemicals for sediment EQS derivation when relevant spiked sediment toxicity data is not available (EC 2011; Burgess et al. 2013; Nowell et al. 2016). The generic term sediment quality guideline (SQG) is used throughout the paper to refer to all of them, independently of the development method and legal enforcement, while standard and criteria denote legal enforcement.

- Probable occurrence based on the compound's hydrophobicity and persistence. The more hydrophobic a compound, the less soluble it is, therefore the more likely to adsorb to soil particles. We used a threshold of log kow $\geq 3$ or $\log$ koc $\geq 3$ for considering a substance as sedimentrelevant in line with the criteria used in other prioritization exercises. Sorption coefficients for sediment $(\mathrm{kd})$ were also searched but the limited availability and large variability of data discouraged its use. Persistence expressed as the half-life (DT50) in soil was an additional criterion for designating a substance as sediment relevant. A threshold value of DT50 $\geq 40 \mathrm{~d}$ was used instead of the threshold of $120 \mathrm{~d}$ established for considering a substance as persistent in sediments (ECHA 2014) as a conservative approach to avoid leaving out substances of potential concern. The different databases in which we searched for persistence indicators are listed as Supplementary Information. When no value was found, we used the qualitative assessment for persistence provided by Daginnus et al (2011), which consider a substance as persistent if the DT50 for freshwater obtained from the BIOWIN or BIOHCWIN modelling from EPI Suite TM 4.0 tool is $>40$ days.

2.1.3. Step 3: classification of substances into action categories

The remaining 240 sediment-relevant substances were sorted into five categories according to data availability and recommendations for action (Fig. 2, Table 1): 
- Category 1: substances with information on environmental concentrations in Switzerland, where a risk factor can be calculated. In the absence of extensive monitoring campaigns dedicated to the sediment compartment in Switzerland, substances that were measured (i) at the national level with broad spatial coverage or (ii) at $>20$ sites were candidates for this category. The substances in this category are potentially recommended substances for regular monitoring programs.

The traditional paradigm for risk assessment was implemented to calculate a risk assessment factor (RAF) for each substance as:

$$
\mathrm{RAF}=\frac{\text { Measured concentration }}{\text { Sediment quality guideline }}
$$

Among the different exposure indicators that can be used as "measured concentration" in the calculation of RAFs depending on data availability (EC 2011; von der Ohe et al. 2011; Olsen et al. 2013), here the $95^{\text {th }}$ percentile of measured concentrations was used and the threshold for classification of substances in Category 1 was set at a RAF $\geq 1$.

- Category 2: substances with limited sediment data in Switzerland or measured environmental concentrations in sediments elsewhere, mainly data from large-scale scientific studies and published reports from EU neighboring countries. Category 2a was used to identify substances measured occasionally in Swiss sediments, where a risk factor can be calculated. RAFs were calculated using maximum measured concentrations, as a worst case scenario for prioritization (Diamond et al. 2011). To avoid excluding substances due to limited data availability, an arbitrary threshold of RAF $\geq 0.1$ was selected for inclusion in this category (Diamond et al. 2011). The number of sites for which data is available is variable and mainly relates to lakes. We identified in Category $2 b$ the substances for which no data is available from Switzerland, but literature data from neighboring EU countries support the need for data acquisition campaigns. Depending on data availability, RAFs were calculated for Category $2 \mathrm{~b}$ substances either as described for Category 1 or Category 2a. 
- Category 3: substances whose risks cannot be assessed are in this category. Substances with no ecotoxicological data where RAFs cannot be calculated are included. A number of substances where assessed through the EqP approach. Although this approach allows to calculate RAFs, improving the ecotoxicological knowledge for sediments is recommended as it should improve the implementation of a proper effect assessment for this environmental compartment.

- Category 4: substances classified as sediment-relevant but without entries of measured sediment concentrations in our data base. The implementation of data acquisition campaigns for substances in this category should be assessed case by case after in-depth analysis of additional environmental concentrations and distribution studies available in the scientific literature. In terms of action categories as such there is no difference in the recommendations for Category 2 and Category 4, they were kept as separate categories because they denote differences in environmental data availability.

- Category 5: monitored substances for which no risk has been identified according to available monitoring data (see Category 1 and 2 for further explanation). In the absence of further evidence, the substances in this category could be subject to reduced routine monitoring. Substances in this category should be assessed individually for the need of further monitoring campaigns, taking into consideration temporal trends and an in-depth analysis of the substance.

\subsubsection{Step 4: ranking of substances}

After classification into action categories substances were ranked according to a simplified version of the NORMAN scoring system. This simplified scoring system used three components, namely the exposure score $(E)$, the hazard score $(H)$ and the risk score $(R)$ :

Final Score $(S)=$ Exposure Score $(E)+$ Hazard Score $(H)+2 \times R i s k$ Score $(R)$ 
The different scores result from adding sub-scores of several indicators as in the NORMAN approach but adapted for Switzerland (Table 2). The exposure score indicates if the substance is still in use, where it is used and if it has been detected in sediments. For example, substances still released to the environment are more relevant for monitoring than those that are banned and no longer used; substances already banned but still released to the environment (e.g. PCBs) were given an intermediate score. The way a substance is used also influences the potential hazard a substance might present. Thus substances directly released to the environment (e.g. pesticides) score the highest (usage pattern sub-score is 1) while substances used in controlled systems score the lowest (sub-score is 0.1 ). Substances that enter the environment continuously via domestic wastewater effluent (e.g. personal care products, pharmaceuticals) and substances with non-dispersive use (e.g. substances used at industrial or local sites) were given intermediate scores (sub-score is 0.75 and 0.5 , respectively; Table 2). Substances that are produced, transported and used in very high quantities are more likely to end up in the environment than those with low production/use volumes. This type of information is usually not readily available and/or confidential and was obtained mainly for plant protection products. This information was used during the expert review for the selection of substance for future data acquisition campaigns when available.

The hazard score was derived based on the following properties of a substance: persistence, bioaccumulation, biomagnification, toxicity and endocrine disrupting potential. The toxicity indicator was based exclusively on the acute LC50 (lethal concentration required to kill $50 \%$ of the population in $48 \mathrm{~h}$ ) for Daphnia sp. This approach presents some limitations for substances that are known to be more sensitive to other organisms than crustaceans such as microlagae. Bioaccumulation was assessed using the bioconcentration factor (BCF) from Daginnus et al. (2011), whereas biomagnification and endocrine disrupting potential were assessed qualitatively using relevant information from several sources (see Table S1 in Supplementary Information). The risk score was 
derived based on the existence or absence of EQS for the sediment compartment in the EU or recommendation of EQS for surface waters in Switzerland, the inclusion of the substance in other lists of priority substances and the calculated RAF. The risk score was multiplied by a factor 2 to give a similar weight to hazard and risk in the final score.

\section{Results and discussion}

3.1. Classification of substances into action categories and ranking

The substances in each category, together with the corresponding score and the calculated RAF are shown in Table 3.

Category 1 and 5: substances recommended for continued and reduced sediment monitoring

Category 1 and 5 provide recommendations for future monitoring of substances with sufficient data. They include contaminants monitored most often in Swiss sediments as well as other chemicals that are not routinely monitored but have been extensively studied in the past. Category 1 includes organochlorine pesticides, hexachlorobenzene, DDT and derivatives, and PAHs and PCBs are included as a group taking into consideration that they are most commonly measured together as a group of compounds or congeners. These substances had measured concentrations above existing SQGs as well as high scores for their PBT properties and exposure relevance. The pseudopersistent bis (2-ethylhexyl) phthalate (DEHP) scored slightly lower than all other substances in this category but it is bioaccumulative, toxic and a potential endocrine disruptor with environmental concentration levels above existing SQGs (RAF > 1). For these substances, proper sediment quality criteria or standards are needed for sediment quality assessment. The routine analysis of these 
compounds in monitoring programs together with ecotoxicological and ecological indicators has helped the process of developing and validating SQGs around the world for many of these substances. Over the past few decades, SQGs have been developed for "traditional" sediment contaminants including PCBs, PAHs and organochlorine pesticides (Wenning et al 2005; de Deckere et al 2011).

Lindane, endosulfan and heptachlor, all of them phased out organochlorine insecticides, appear most often at concentrations below SQGs and may be recommended for reduced routine monitoring in the absence of other evidence (Category 5 ). The need of further monitoring activities should be assessed individually for each substance, taking into consideration usage patterns and areas where concentrations may become of concern or pose a risk to the environment. For some PAHs (e.g. fluoranthene, anthracene, phenanthrene) measured environmental concentrations were frequently below SQGs and would therefore be assigned to Category 5.

Category 2 and 4: substances recommended for data acquisition campaigns and screening studies on exposure

Category 2 identifies substances measured occasionally in the country or included in more extended programs in Europe. For these, data acquisition campaigns are recommended. Irgarol, triclosan, diuron and benzo(e)pyrene were previously quantified in Swiss sediments at concentrations that may pose environmental risks (concentrations above existing SQGs). These substances, which are classified in Category $2 \mathrm{a}$ according to availability of environmental data from Swiss sediments, were also above existing SQGs when data from other EU countries were considered, and had the highest scores within this category. Different contaminant properties and input patterns result in differences in the exposure, hazard and risk sub-scores. They are all WFD 
priority pollutants or on the watch list. Triclosan scored higher in the hazard score than diuron and irgarol according to its persistence, bioaccumulation potential and endocrine disrupting properties. Irgarol is an algaecide widely used in long-life antifouling coatings and - like diuron - as an herbicide. Both, irgarol and diuron, scored higher with regard to exposure than triclosan, which is banned as a biocide in Switzerland but is still permitted in certain personal care products and cosmetics. The toxicity indicator in the scoring system here may have underscored irgarol and diuron because are known to be more toxic to algae than crustaceans, the indicator species used here, although the use of alternative toxicity indicators would not have changed the resulting topranked substances.

Substances that were present at concentrations below SQGs but still above the threshold (RAFs between 0.1 and 1) include terbutylazine, terbutryn, pirimicarb and dinoseb. These four substances are also recommended for additional data acquisition actions. Several herbicides, fungicides and insecticides were also classified in Category $2 \mathrm{a}$ but the levels of measured concentrations were well below the corresponding SQGs $(\mathrm{RAF}<0.1)$. Although rather scarce, available data allowed an initial screening that suggests reduced monitoring efforts in sediments for these substances. Tebuconazole, isoproturon, cyprodinil, pyrimethanil, propiconazole, flusilazole, DEET, methylbenzotriazole, penconazole and atrazine are among the substances in this situation.

Category $2 \mathrm{~b}$ identified substances with no data from Switzerland but available data from elsewhere. The highest scores in this subcategory were obtained for carbamazepine and estron, with similar exposure scores, but carbamazepine had a higher risk score and estron a higher hazard score due to persistence. Pharmaceuticals and hormones are monitored in surface waters but few data are available of environmental concentrations in the sediment compartment for Switzerland are available. Other substances in this situation include the pyrethroid insecticides deltamethrin, 
lambda-cyhalothrin and permethrin, and the organophosphate insecticide chlorpyriphos, with high hazard scores. Bisphenol-A is also in Category $2 b$ with levels of concentrations above SQGs and scored high in exposure.

Category 4 included substances that met at least one of the criteria for being considered as sediment-relevant but had not been investigated in Switzerland and no monitoring data for the sediment compartment was included in our database. Many fungicides (captan, cyproconazole, dichlofluanid, fenbuconazole, fluazinam, flunquiconazole, folpet, metconazole, picoxytrobin, quinoxyfen, totylfluanid), herbicides (acloxifen, bifenox, flufenacet and triclopyr) and insecticides (chlorfenvinphos, cyfluthrin, diflubenzuron, teflubenzuron, toxaphene) fell in this category. Boscalid, cyproconazole, tebuconazole, cyprodinil and pyrimethanil, which are included in the Swiss priority list for contaminants from non-point sources (Wittmer et al. 2014) and are sediment-relevant, were also classified in Category 4. Diclofenac, 17- $\alpha$-Ethinylestradiol and 17- $\beta$-Estradiol, the antibiotic erythromycin and the lipid-lowering agent bezafibrat have been also identified in the EU lists of substances recommended for water monitoring and in previous prioritization exercises performed in Switzerland (Perazzolo 2008; Götz et al. 2010), but there is scattered environmental data for the sediment compartment relevant for this situation analysis. Other pharmaceuticals included in this category were atenolol, azithromycin, ciprofloxacin, clarithromycin, fenofibrate, fluoxetine, ibuprofen, ivermectin, ketoprofen, mefenamic acid, and propranolol among others. Some discrepancies are apparent with the definition of this category, as there are numerous studies on environmental concentrations and distribution of these compounds in the scientific literature not considered here (e.g. Cavaliere et al. 2016; Pintado-Herrera et al. 2016; Pinto et al. 2016). This substantial body of literature should be assessed for reliability and relevance in the selection of substances for further data acquisition campaigns at a later stage. 
Category 3: substances recommended for improvement of ecotoxicological knowledge

Category 3 identified substances for which the risk could not be assessed in the absence of SQGs. The pesticides octhilinone (OIT) and tebutam, the fungicides prochloraz, fenpropimorph and fludioxonil are in this category. It was also not possible to make the risk assessment to a large extent for emerging substances used in personal care products such as climbazol, triclocarban, octocrylene, synthethic musks such as tonalide and galaxolid and its degradation products, and surfactants. It is significant that a large number of substances was assessed using SQGs derived without effect data for relevant benthic species nor spiked-sediment exposures, but rather by using the Equilibrium Partitioning (EqP) approach described in the Directive on EQSs (EC 2013). The Directive on EQSs is focused on surface waters but, if justified, countries can establish EQSs at a national level in sediments and biota (EC 2013). The suitability of the sediment compartment for the monitoring of certain WFD priority pollutants is promoting the development of EQS for sediments despite an apparent lack of spiked-sediment toxicity data for many organic substances. For nonionic substances water EQSs can be translated into sediment quality guidelines using the EqP approach, although ecotoxicological effect data for species representative of the sediment compartment should be ideally used in the development process (EU 2011; ECHA 2013). Perfluorinated compounds and polybrominated diphenyl ethers (PBDEs) are among the top ranked substances with increasing detection in the environment but limited ecotoxicological data for the sediment compartment. Environment Canada (2013) have developed quality guidelines for some BDEs, including for sediments. For PFOS, quality guidelines for surface waters have been developed but not for sediments. Risk assessments for such sediment-relevant substances would greatly benefit from more ecotoxicological studies with relevant benthic species.

3.2. Uncertainties and recommendations 
The screening system as presented here has several uncertainties and limitations. One important limitation is related to the lack of appropriate analytical methods for sediments and resulting questions regarding relevance of the list of candidate substances. From the initial list of 1080 entries we retained a limited number of substances for classification and scoring that met at least one of the following criteria: 1) proven occurrence of the substance in the sediment compartment; 2) availability of SQGs or EQSs; 3) probable occurrence based on the compound's hydrophobicity and persistence. This initial screening study left out substances that may not have a traditional persistent and bioaccumulative profile but may still be a potential risk either as parent compound or degradation product, simply because they have not been previously quantified in sediments. There are several tens of thousands of organic chemicals on the market and existing monitoring programs cover only a small selection of them. Because monitoring is a legal requirement under the WFD, sensitive and accurate analytical methods are required in water and sediment quality management. To fulfill the validation requirements, the analytical methods developed must meet the technical specifications for chemical analysis and monitoring of water status, sediment and biota stated in Directive 2009/90/EC (EC 2009). To ensure comparability of the results the limit of quantification (LOQ) of the analytical method must be equal or below a value of $30 \%$ of the relevant EQS and the uncertainty of the results must be $50 \%$ or below the estimated EQS with a coverage factor of 2 ( $k=$ 2) corresponding to a level of confidence of approximately $95 \%$ (EC 2009). The use of standardized methods is recommended in water monitoring programs but only a few standard methods exist for sediment analysis (Loos 2012, Pinto et al. 2016). Many substances are, at most, investigated in specific projects. Such data were largely excluded here resulting in some discrepancies between substances classified in Category 4 and existing scientific literature. The NORMAN prioritization approach includes an additional category for substances that require improvement of analytical methods because analytical capabilities are not yet satisfactory (Dulio and von der Ohe 2013). This sixth category was not included in our exercise, an in-depth evaluation taking into consideration 
identified risks and uncertainty of analytical measurements and SQGs is required for the selection or deselection of substances for monitoring in the sediment compartment. Regarding the sensitivity of the ranking algorithm, the increase in the final prioritization score resulting from the inclusion of supporting data would not change the top-ranked substances in Category 2 and 4.

Following the recommendation to monitor some of the priority substances in sediments by EU member states and the availability of guidance documents for its development (EU 2011; ECHA 2013), the number of SQGs is progressively increasing (Dueri et al. 2008; EC 2012; Maggi et al. 2012). The SQGs used in this exercise came from different sources and were derived using different methods, however, only effect-based values were considered (i.e. direct toxicity measurements were used in their development). For a number of non-ionic substances the risks were assessed by translating EQSs for surface waters into SQGs using the EqP approach. High uncertainty due to limited effect data is also behind large safety factors resulting in relatively low EQSs for water and high RAF values. Although the EqP is common practice in the absence of sediment data, SQS based on toxicity data for sediment organisms would be more relevant and robust. In addition, for substances that are potentially bioaccumulated and biomagnified, sediment contamination may have other far-reaching biological effects that may not be apparent from sediment toxicity tests with benthic organisms. Bioaccumulation and biomagnification potential was taken into consideration in the hazard assessment but not for SQGs derivation, thus the RAF does not include risk through secondary poisoning.

In addition to the PBT properties, the listing of a substance as a priority compound elsewhere was an important determinant for our final prioritization score. Given the limited number of environmental data for Swiss sediments, which limited our ability to screen for relevant substances, it was necessary to build on the results of prioritizations done by other countries. In the case of 
sediments, substances should be selected for monitoring taking into consideration ongoing efforts in the water phase, which is common practice in many countries including Switzerland. In sediments, both current-use substances as well as compounds regulated or banned for decades ("legacy contaminants") may be contaminants of concern. For chemicals that have been recently regulated or are under evaluation, data acquisition campaigns may be needed if information on environmental concentrations and temporal trends is lacking. At present, any list of candidate substances for sediment monitoring has to be preliminary, because additional data is needed. In this sense, an adaptive monitoring strategy based on a robust experimental design, high-quality data collection and extensive collaboration between managers, scientists and stakeholders would benefit the implementation of effective sediment quality monitoring and assessment programs (e.g. Maruya et al. 2014; Karahan-Ozgun et al. 2017).

\section{Acknowledgements}

The authors wish to thank the advisory group of the project for the development of a module sediment for Switzerland (Marc Babut, Felippe Deallencastro, Nathalie Dubois, Stefan Gautschi, Christian Goetz, Pascal Nirel, Rico Ryser, Serge Santiago, Jurg Sinniger, Nele Schuwirtz) and in particular the prioritization working group (Nathalie Chèvre, Juliane Hollender, Robert Kase, JeanLuc Loizeau, Christian Michel, Irene Wittmer and Christoph Reusser). We also acknowledge Aurea Chiaia-Hernandez and CIPEL, who provided environmental data, and the anonymous reviewers for their valuable comments and suggestions to improve the quality of the paper.

\section{References}

Al-Khazrajy OS, Boxall AB (2016) Risk-based prioritization of pharmaceuticals in the natural environment in Iraq. Environ Sci Pollut Res 23:15712-15726 
Besse JP, Garric J (2008) Human pharmaceuticals in surface waters. Implementation of a prioritization methodology and application to the French situation. Toxicol Lett 176: 104-123

Bu Q, Wang D, Wang Z (2013) Review of screening systems for prioritizing chemical substances. Crit Rev Env Sci Tec 43:1011-104

Burgess RM, Berry WJ, Mount DR, Di Toro DM (2013) Mechanistic sediment quality guidelines based on contaminant bioavailability: equilibrium partitioning sediment benchmarks. Environ Toxicol Chem $32: 102-114$

Cavaliere C. Capriotti A-L, Ferraris F, Foglia P, Samperi R, Ventura S, Laganà A (2016) Multiresidue analysis of endocrine-disrupting compounds and perfluorinated sulfates and carboxylic acids in sediments by ultra-high-performance liquid chromatography-tandem mass spectrometry. J Chromatog A 1438:133-142

Daginnus K, Gottardo S, Payá-Pérez A, Whitehouse P, Wilkinson H, Zaldivar JM (2011) A modelbased prioritisation exercise for the European Water Framework Directive. Int J Environ Res Public Health 8:435-455

de Deckere E, De Cooman W, Leloup V, Meire P, Schmitt C, von der Ohe PC (2011) Development of sediment quality guidelines for freshwater ecosystems. J Soils Sed11:504-517 
Diamond JM, Latimer II HA, Munkittrick KR, Thornton KW, Bartell SM, Kidd KA (2011) Prioritizing contaminants of emerging concern for ecological screening assessments. Environ Toxicol Chem 30:2385-2394

Di Nica V, Menaballi L, Azimonti G, Finizio A (2015) RANKVET: a new ranking method for comparing and prioritizing the environmental risk of veterinary pharmaceuticals. Ecol Indic 52:270276

Donnachie RL, Johnson AC, Sumpter JP (2016) A rational approach to selecting and ranking some pharmaceuticals of concern for the aquatic environment and their relative importance compared with other chemicals. Environ Toxicol Chem 35:1021-1027

Dueri S, Castro-Jiménez J, Zaldibar JM (2008) On the use of the portioning approach to the derived Environmental Quality Standards (EQS) for persistent organic pollutants (POPs) in sediments: a review of existing data. Sci Total Environ 403:23-33

Dulio V, Von der Ohe PC (2012) NORMAN prioritisation framework for emerging substances. Publisher: NORMAN Association. ISBN: 978-2-9545254-0-2

Environment Canada (2013) Canadian Environmental Protection Act, 1999 -Federal Environmental Quality Guidelines Polybrominated Diphenyl Ethers (PBDEs), 25

European Chemical Agency (ECHA) (2013) Proceedings of the Topical Scientific Workshop on Risk Assessment for the Sediment Compartment, Helsinki May 2013 
European Chemical Agency (ECHA) (2014) Guidance on Information Requirements and Chemical Safety Assessment, Chapter R.11: PBT/vPvB Assessment, Helsinki 2014

European Commission (EC) (2009) Commission Directive 2009/90/EC of 31 July 2009 laying down, pursuant to Directive 2000/60/EC of the European Parliament and of the Council, technical specifications for chemical analysis and monitoring of water status. Off. J. Eur. Communities L201, $36(01.08 .2009)$

European Commission (EC) (2010) WFD-CIS Guidance Document No. 25: Guidance on chemical monitoring of sediment and biota under the Water Framework Directive. Office for Official Publications of the European Communities, Luxembourg, p. 74.

European Commission (EC) (2011) Common implementation strategy for the Water Framework Directive (2000/60/EC). Guidance document No: 27. Technical guidance for deriving Environmental Quality Standards

European Commission (EC) (2012) Report from the Commission to the European Parliament and the Council on the implementation of the Water Framework Directive (2000/60/EC) river basin management plans. $\operatorname{COM}(2012) 670$ Final 
European Commission (EC) (2013). Directive 2013/39/EU of the European Parliament and of the Council of 12 August 2013 amending Directives 2000/60/EC and 2008/105/EC as regards priority substances in the field of water policy (24.08.2013) Off J Eur Union L226 (2013), p. 1

Flück R, Campiche S, de Alencastro LF, Ferrari BJD, Rossi L, Santiago S, Werner I, Chèvre N (2012) Surveillance de la qualité des sédiments. État actuel des méthodes disponibles et mise en place de recommandations. Aqua \& Gas 4, Avril 2012

Götz CW, Stamm C, Fenner K, Singer H, Schärer M, Hollender J (2010) Targeting aquatic microcontaminants for monitoring: exposure categorization and application to the Swiss situation. Environ Sci Pollut Res 17:341-354

Guo J, Sinclair CJ, Selby K, Boxall AB (2016) Toxicological and ecotoxicological risk-based prioritization of pharmaceuticals in the natural environment. Environ Toxicol Chem 35:1050-1059

Homem V, Silva JA, Ratola N, Santos L, Alves A (2015) Prioritisation approach to score and rank synthetic musk compounds for environmental risk assessment. J Chem Technol Biotechnol $90: 1619-1630$

James A, Bonnomet V, Morin A, Fribourg-Blanc B (2009) Implementation of requirements on priority substances within the context of the Water Framework Directive. Prioritization process: Monitoringbased ranking, p. 58 
Karahan-Ozgun O, Basak B, Eropak C, Abat S, Kirim G, Girgin E, Hanedar A, Gunes E, Citil E, Görgün E, Yangin-Gomec C, Germirli-Babuna F, Ovez S, Tanik A, Ozturk I, Kinaci C, Karaaslan Y, Mine-Gucver S, Siltu E, Koc-Orhon A (2017) Prioritization methodology of dangerous substances for water quality monitoring with scarce data. Clean Techn Environ Policy 19:105-122

Loos R (2012) Analytical methods for the new proposed priority substances of the European Water Framework Directive (WFD). Revision of the Priority Substance List (2012). JRC Technical Reports.

MacDonald DD, Ingersoll CG, Berger TA (2000) Development and evaluation of consensus-based sediment quality guidelines for freshwater ecosystems. Arch Environ Contam Toxicol 39:20-31

Maggi C, Ausili A, Boscolo R, Cacciatore F, Bonometto A, Cornello M, Berto D (2012)

Sediment and biota in trend monitoring of contaminants in transitional waters. TrAC Trends Anal Chem 36:82-91

Maruya KA, Schlenk D, Anderson PD, Denslow ND, Drewes JE, Olivieri AW, Scott GI, Snyder SA (2013) An adaptive, comprehensive monitoring strategy for chemicals of emerging concern (CECs) in California's aquatic ecosystems. Integr Environ Assess Manag 10:69-77

Nowell LH, Norman JE. Ingersoll CG, Moran PW (2016) Development and application of freshwater sediment-toxicity benchmarks for currently used pesticides. Sci Tot Environ 550:835-850

Office Fédéral de la Protection de l'Environnement (OFEV) (1998) Ordonnance du 28 octobre 1998 sur la protection des eaux (OEaux). No. RS 814.201. Berne, Switzerland 
Olsen LD, Valder JF, Carter JM, Zogorski JS (2013) Prioritization of constituents for national- and regional-scale ambient monitoring of water and sediment in the United States. US Geological Survey Scientific Investigations Report 2012-5218, 203p, plus supplemental tables, http://pubs.usgs.gov/sir/2012/5218/

Perrazzolo C (2008) Détermination d'une liste prioritaire de medicaments. Application à quelques groups de substances. Université de Lausanne, Switzerland. 72 pp

Pintado-Herrera MG, Gonzalez-Mazo E, Lara-Martin PA (2016) In-cell clean-up pressurized liquid extraction and gas chromatography-tandem mass spectrometry determination of hydrophobic persistent and emerging organic pollutants in coastal sediments. J Chrom A 1429: 107-118

Pinto MI, Burrows HD, Sontag G, Vale C, Noronha JP (2016) Priority pesticides in sediments of European coastal lagoons: A review. Mar Poll Bull 1-2:6-16

RIVM (2010) Environmental risk limits for PFOS. A proposal for water quality standards in accordance with the Water Framework Directive. Report 601714013/2010. National Institute for Public Health and the Environment, Bilthoven, the Netherlands.

Slobodnik J, Mrafkova L, Carere M, Ferrara F, Pennelli B, Schüürmann G, von der Ohe PC (2012) Identification of river basin specific pollutants and derivation of environmental quality standards: a case study in the Slovak Republic. Trends Anal Chem 41:133-145 
Smital T, Terzić S, Lončar J, Senta I, Žaja R, Popović M, Mikac I, Tollefsen KE, Thomas KV, Ahel M (2013) Prioritisation of organic contaminants in a river basin using chemical analyses and bioassays. Environ Sci Pollut Res 20: 1384-1395

Tsaboula A, Papadakis EN, Vryzas Z, Kotopoulou A, Kintzikoglou K, Papadopoulou-Mourkidou E (2016) Environmental and human risk hierarchy of pesticides : a prioritization method, based on monitoring, hazard assessment and environmental fata. Environ Int 91:78-93

Von der Ohe PC, Dulio V, Slobodnik J, De Deckere E, Kühne R, Ebert RU, Ginebreda A, De Cooman W, Schüürmann G, Brack W (2011) A new risk assessment approach for the prioritization of 500 classical and emerging organic microcontaminants as potential river basin specific pollutants under the European Water Framework Directive. Sci Total Environ 409:2064-2077

Wenning R, Batley RJ, Ingersoll CG, Moore DW, editors (2005) Use of sediment quality guidelines and related tools for the assessment of contaminated sediments. Pensacola (FL): Society of Environnemental Toxicology and Chemistry (SETAC), $815 p$

Wittmer I, Junghans M, Singer H, Stamm C (2014) Micropolluants - Stratégie d'évaluation pour les micropolluants organiques de sources non ponctuelles. Etude réalisée sur mandat de l'OFEV. Eawag, Dübendorf, $\mathrm{CH} .104 \mathrm{p}$ 
Figure captions

Fig. 1 Flowchart used for the prioritization of substances (after Dulio and Von der Ohe, 2012)

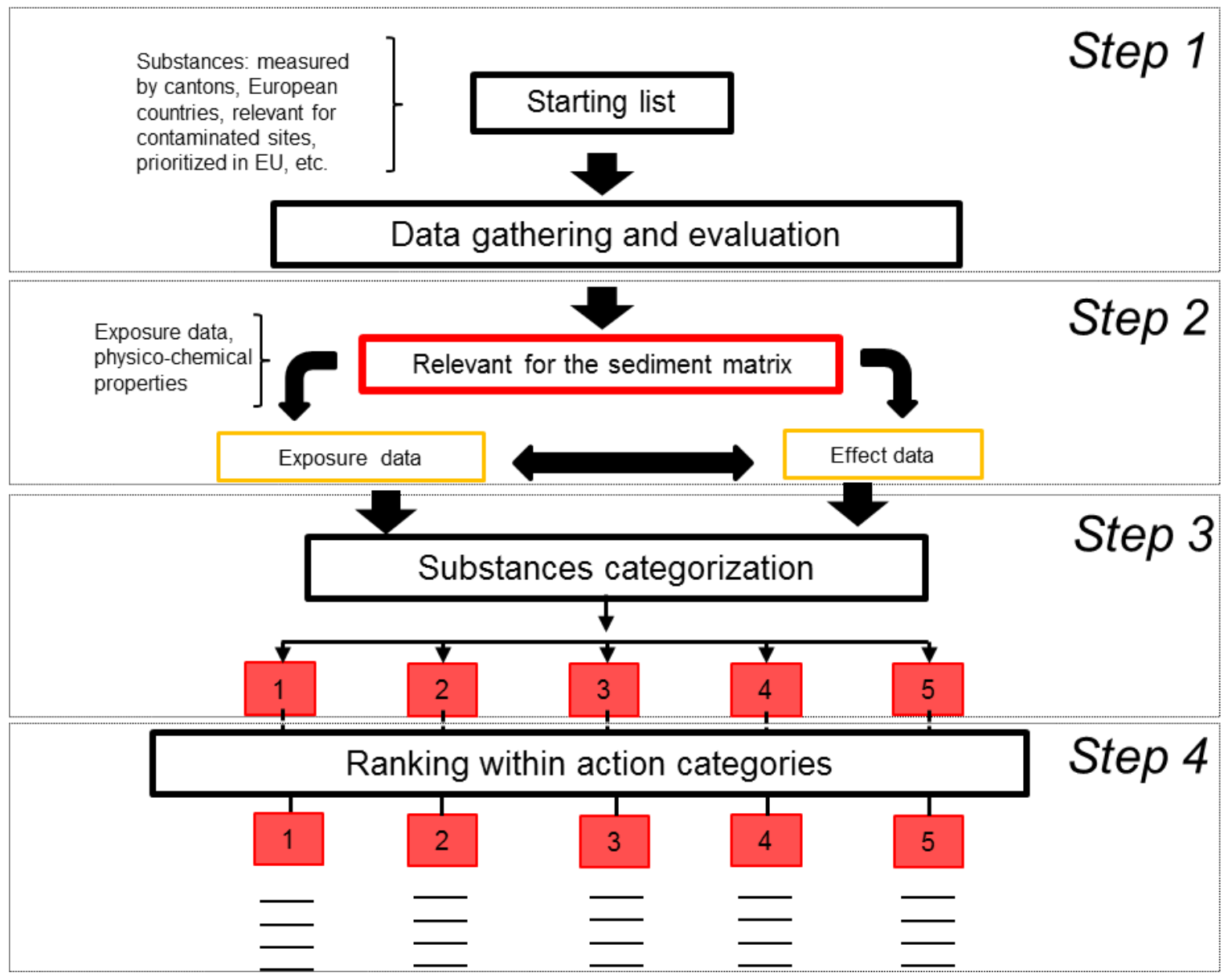


Fig. 2 Flowchart used for the classification of substances into action categories

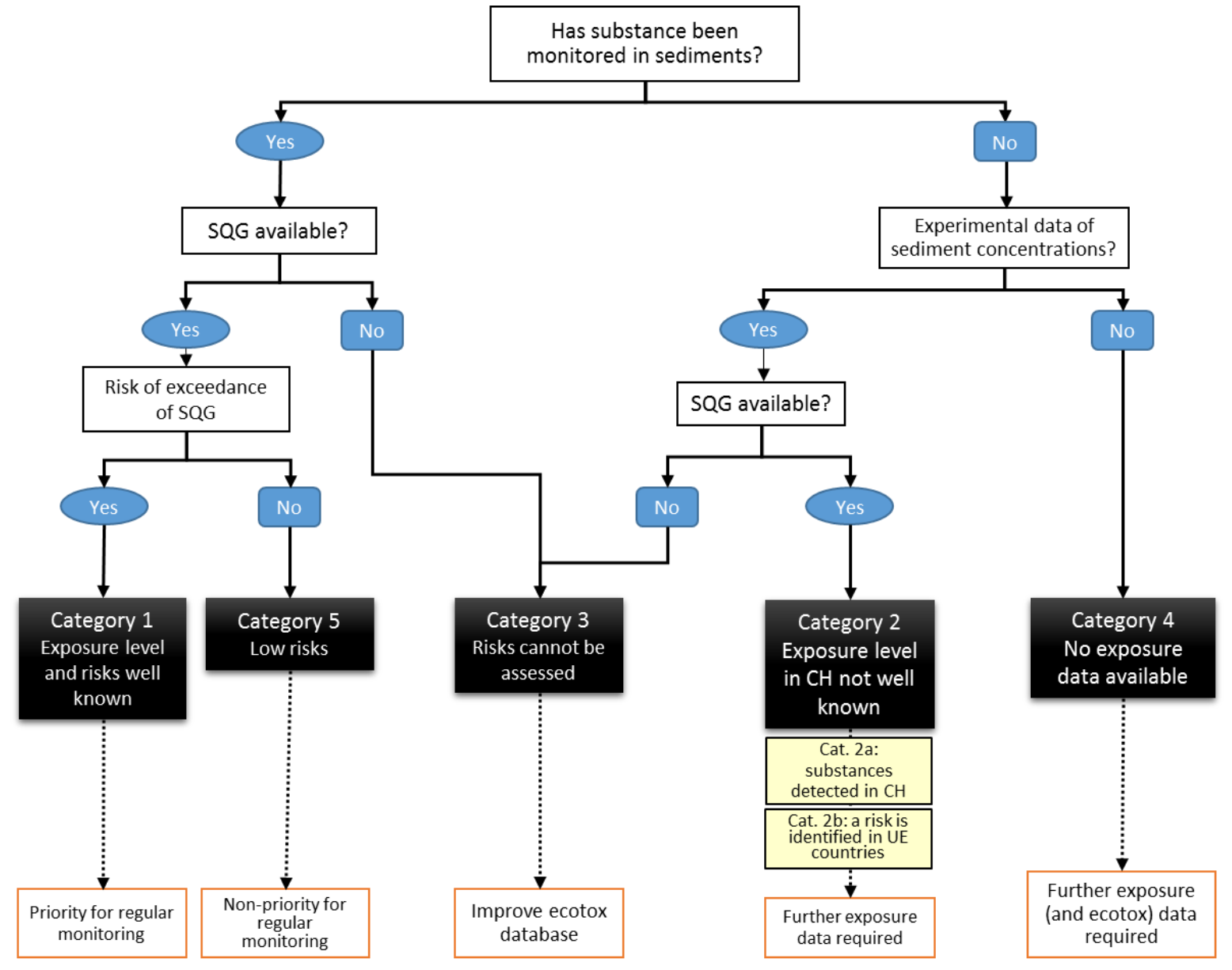


Table 1. Categories according to present knowledge and actions that should be implemented.

\begin{tabular}{|c|c|c|c|c|c|}
\hline Category & 1 & 2 & 3 & 4 & 5 \\
\hline Situation & $\begin{array}{l}\text { Exposure level and risks are } \\
\text { known. }\end{array}$ & $\begin{array}{l}\text { Exposure level is not well } \\
\text { known. }\end{array}$ & $\begin{array}{l}\text { Risks cannot be } \\
\text { assessed. }\end{array}$ & $\begin{array}{l}\text { Substance with limited } \\
\text { environmental data. }\end{array}$ & $\begin{array}{l}\text { Substances } \\
\text { monitoring data and no } \\
\text { identified risks. }\end{array}$ \\
\hline Criteria & $\begin{array}{l}\text { Levels of concentrations in } \\
\text { Switzerland are relatively } \\
\text { well known. } \\
\text { SQGs are available. A risk } \\
\text { is identified according to } \\
95^{\text {th }} \text { Percentile (RAF } \geq 1 \text { ). }\end{array}$ & $\begin{array}{l}\text { Substances measured } \\
\text { occasionally in } \mathrm{CH} \text { or } \\
\text { measured in other EU } \\
\text { countries. }\end{array}$ & $\begin{array}{l}\text { Substances } \\
\text { measured in } \mathrm{CH} \\
\text { and EU countries. } \\
\text { Ecotoxicological } \\
\text { data are missing. }\end{array}$ & $\begin{array}{l}\text { Substances identified as } \\
\text { sediment-relevant } \\
\text { according to physico- } \\
\text { chemical properties or } \\
\text { supporting studies. }\end{array}$ & $\begin{array}{l}\text { Substances with a RAF }<1 \\
\text { according to } 95^{\text {th }} \\
\text { Percentile, decreasing } \\
\text { concentrations or banned } \\
\text { in Switzerland. }\end{array}$ \\
\hline $\begin{array}{l}\text { Actions to } \\
\text { implement }\end{array}$ & $\begin{array}{l}\text { Candidate substances for } \\
\text { regular monitoring } \\
\text { programs. } \\
\text { Quality criteria needed for } \\
\text { sediment quality } \\
\text { assessment. }\end{array}$ & $\begin{array}{l}\text { Measurement campaigns } \\
\text { for data acquisition. }\end{array}$ & $\begin{array}{l}\text { Improvement of } \\
\text { ecotoxicological } \\
\text { knowledge. }\end{array}$ & $\begin{array}{l}\text { Implementation of data } \\
\text { acquisition campaigns. } \\
\text { (Development of } \\
\text { analytical and } \\
\text { ecotoxicity knowledge if } \\
\text { necessary). }\end{array}$ & $\begin{array}{l}\text { Substances that could be } \\
\text { subject to reduced routine } \\
\text { monitoring in the absence } \\
\text { of other evidence. }\end{array}$ \\
\hline
\end{tabular}


Table 2. Indicators and algorithm used for ranking substances within action categories.

\begin{tabular}{|c|c|c|c|}
\hline Score & Indicator & Sub-score* & Range Score \\
\hline Exposure & $\begin{array}{l}\text { Compound in use } \\
\text { Usage pattern } \\
\text { Existing monitoring } \\
\text { data in Switzerland }\end{array}$ & $\begin{array}{l}\text { Yes: } 1 \\
\text { No: } 0 \\
\text { Not used but still released: } 0.5 \\
\text { Used in the environment: } 1 \\
\text { Wide dispersive use: } 0.75 \\
\text { Non-dispersive use: } 0.5 \\
\text { Controlled system: } 0.1 \\
\text { In Switzerland: } 1 \\
\text { Elsewhere: } 0.5 \\
\text { In CH and elsewhere: } 1.5 \\
\text { No data: } 0\end{array}$ & $0.1-3.5$ \\
\hline Hazard & $\begin{array}{l}\text { Persistence } \\
\text { Bioaccumulation } \\
\text { Biomagnification } \\
\text { Toxicity ( } \mu \mathrm{g} / \mathrm{L}) \\
\text { Potential endocrine } \\
\text { disrupting effects }\end{array}$ & $\begin{array}{l}\text { Yes: } 1 \\
\text { No: } 0 \\
\text { Log }(\mathrm{BCF}) \geq 3.3 ; \mathrm{B}, \mathrm{vB}: 1 \\
\text { Log }(\mathrm{BCF}) \geq 2.7 ; \text { suspected B: } 0.5 \\
\text { No data: } 0.1 \\
\text { Not B: } 0 \\
\text { Yes: } 1 \\
\text { Suspect: } 0.5 \\
\text { No data: } 0.1 \\
\text { No: } 0 \\
\leq 0.1 \text { (T, T+): } 1 \\
\leq 1 \text { (potentially T): } 0.5 \\
\leq 10 \text { (potentially not } \mathrm{T}): 0.1 \\
\text { Low toxicity: } 0 \\
\text { Yes: } 1 \\
\text { Suspect: } 0.5 \\
\text { No data: } 0.1 \\
\text { No: } 0\end{array}$ & $0-5$ \\
\hline Risk & $\begin{array}{l}\text { Priority substance } \\
\text { elsewhere } \\
\text { Existing quality } \\
\text { criteria }\end{array}$ & $\begin{array}{l}\text { No data: } 0.5 \\
\leq 0.1: 0 \\
0.1-0.5: 0.25 \\
0.5-1: 0.5 \\
\text { 1-10: } 0.75 \\
\geq 10: 1 \\
\text { Yes: } 1 \\
\text { No: } 0 \\
\text { Existing EQS } \text { sed }_{1} 1 \\
\text { Existing recommendation of } \\
\text { EQS } \\
\text { Nater in Switzerland: } 0.5\end{array}$ & $0-3$ \\
\hline
\end{tabular}

*B: bioaccumulative; $\mathrm{T}$ : toxic 
Table 3. Results of the classification of substances in action categories and scoring. RAF: risk assessment factor.

\begin{tabular}{|c|c|c|c|c|c|c|c|c|}
\hline \multicolumn{3}{|l|}{ Category 1} & \multicolumn{3}{|c|}{ Category 2a } & \multicolumn{3}{|c|}{ Category $2 b$} \\
\hline Substance & Score & RAF & Substance & Score & RAF & Substance & Score & RAF \\
\hline Hexachlorobenzene & 13.0 & 1000 & Triclosan & 13.3 & 1.7 & Carbamazepin & 9.5 & 0.6 \\
\hline PCBs & $12.5-10.5$ & $\leq 16$ & Diuron & 11 & 1.0 & Estron & 9 & 1.5 \\
\hline $\mathrm{PAHs}$ & $12.4-8.9$ & $\leq 2.3$ & Irgarol-Cybutryne & 10.2 & 40 & Deltamethrin & 8.5 & 14 \\
\hline DDT and derivatives & 10.5 & 39 & Benzo(e)pyrene & 9.8 & 37 & Chlorpyrifos & 8.5 & 2.1 \\
\hline \multirow[t]{16}{*}{ Bis (2-ethylhexyl) phthalate } & 9.3 & 1.5 & Terbutylazine & 9.2 & 0.2 & Lambda-Cyhalothrin & 8.1 & 1.9 \\
\hline & & & Terbutryn & 8.5 & 0.2 & Bisphenol-A & 6.3 & 1.3 \\
\hline & & & Pirimicarb & 7.6 & 0.61 & Permethrin & 6 & 1.1 \\
\hline & & & Dinoseb & 3.2 & 0.6 & Dibutylphthalate & 5.9 & 1.0 \\
\hline & & & Tebuconazole & 9.1 & $<0.1$ & Dibutyltin cation & 7.1 & 0.1 \\
\hline & & & Isoproturon & 8.1 & $<0.1$ & Iprodione & 6.7 & $<0.1$ \\
\hline & & & Cyprodinil & 8.1 & $<0.1$ & Pendimethalin & 6.5 & $<0.1$ \\
\hline & & & Pyrimethanil & 7.7 & $<0.1$ & Prometryn & 6.1 & $<0.1$ \\
\hline & & & Propiconazole & 7.3 & $<0.1$ & Piperonyl butoxide & 4.1 & $<0.1$ \\
\hline & & & Flusilazole & 7.1 & $<0.1$ & & & \\
\hline & & & DEET & 6.2 & $<0.1$ & & & \\
\hline & & & Methylbenzotriazol & 5.7 & $<0.1$ & & & \\
\hline & & & Penconazole & 5.3 & $<0.1$ & & & \\
\hline & & & Atrazine & 5.2 & $<0.1$ & & & \\
\hline & & & Prometon & 4.7 & $<0.1$ & & & \\
\hline & & & Difenoconazole & 3.8 & $<0.1$ & & & \\
\hline
\end{tabular}




\section{SUPPLEMENTARY INFORMATION}

Table S1: Origin of the data used in the prioritization exercise

\begin{tabular}{llll}
\hline Name & Description & Parameter & Provenance / confidentiality \\
\hline a) Main source & & & Last update \\
\hline Uchem databank & $\begin{array}{l}\text { Extract for 852 substances from the databank } \\
\text { of the Uchem department at EAWAG }\end{array}$ & $\begin{array}{l}\text { Legal aspects, exposure in } \\
\text { Switzerland (measured } \\
\text { environmental concentrations in } \\
\text { surface waters), environmental } \\
\text { fate, ecotoxicological information }\end{array}$ \\
\hline
\end{tabular}

b) Data used/added to assess persistence, hydrophobicity

IGS-Check 2014

Swiss information system for dangerous substances

ECHA

CIRCABC

INERIS

PubChem

HSDB-TOXNET
Obtaining data and information on persistence and toxicity of substances from the ECHA (European Chemicals Agency) dossiers

Obtaining data and information on persistence and toxicity of substances from substances dossiers stored at the EU CIRCABC

(Communication and Information Resource Centre for Administrations, Businesses and Citizens)

Obtaining quality standards for sediment and environmental fate values from the French INERIS (Institut national de l'environnement industriel et des risques) data base

Databank for chemical substances maintained by the US National Center for Biotechnology Information (NCBI)
Physico-chemical parameters (Kow, soil DT50)

University of Hertfordshire (UK)

2014-2015

Name of substances, legal

aspects, Cas- $\mathrm{Nr}$, environmenta

Swiss confederation, FOCP, NAZ, open

access for Swiss Federal Institute

ECHA, open source

Kow, persistence, toxicity

$\mathrm{K}_{\text {sed-water, }}$ Kow, BCF, persistence

CIRCABC, open source

QSsed, DT50 soil and Kow

INERIS, open source

Log (P), DT50, persistence

National Institute of Heath

Continually
Continually

2014

Depending of the year of dossier publication

Depending of the year of dossier publication

Continually 


\begin{tabular}{|c|c|c|c|c|}
\hline Name & Description & Parameter & Provenance / confidentiality & Last update \\
\hline & $\begin{array}{l}\text { Obtaining data and information on } \\
\text { environmental fate of substances from the } \\
\text { Hazardous Substances Data Bank (HSDB). }\end{array}$ & & $\begin{array}{l}\text { U.S. National Library of Medicine's (NLM) } \\
\text { Toxicology Data Network (TOXNET). }\end{array}$ & \\
\hline WFD & $\begin{array}{l}\text { Model-Based Prioritization Exercise- } \\
\text { supplementary data. Biodegradability, } \\
\text { persistence calculated by BIOWIN (rapid } \\
\text { aerobic biodegradation of an organic } \\
\text { substance) and BIOCHIN (half-life prediction of } \\
\text { petroleum hydrocarbons) calculated by EPI } \\
\text { Suite TM v4.0 tool. }\end{array}$ & $\begin{array}{l}\text { Readily biodegradable: yes/no } \\
\text { Persistence }\end{array}$ & Publication, Daginnus et al. (2011) & 2011 \\
\hline \multicolumn{5}{|c|}{ c) Data used/added to assess toxicity } \\
\hline $\begin{array}{l}\text { Ecotox Centre EQS } \\
\text { proposals }\end{array}$ & $\begin{array}{l}\text { Quality criteria for water adapted for sediment } \\
\text { using the EqP approach according to the UE } \\
\text { Technical Guidance Document } n^{\circ} 27\end{array}$ & QC water fw & $\begin{array}{l}\text { Swiss Centre for Applied Ecotoxicology } \\
\text { Open source }\end{array}$ & Continually \\
\hline INERIS proposals & $\begin{array}{l}\text { Guidance value for protecting sediment- } \\
\text { dwelling organisms. Only GV derived using the } \\
\text { AF approach from experimental data have } \\
\text { been considered }\end{array}$ & GC sediment fw & INERIS, open source & Continually \\
\hline $\begin{array}{l}\text { Umwelt Bundesamt } \\
\text { Deutschland proposals }\end{array}$ & $\begin{array}{l}\text { Quality Standards for protecting sediment- } \\
\text { dwelling organisms. Only QS derived using the } \\
\text { AF approach from experimental data have } \\
\text { been considered }\end{array}$ & QS sediment fw & $\begin{array}{l}\text { Revision der Umweltqualitätsnormen der } \\
\text { Bundes, TEXTE } 47 / 2015\end{array}$ & 2015 \\
\hline REACH & $\begin{array}{l}\text { Predicted No Effect Concentrations (PNECs) } \\
\text { for protecting sediment-dwelling organisms }\end{array}$ & PNECsed & REACH, open source & Continually \\
\hline Footprint databank & Information on plant protection products & $\begin{array}{l}\text { Aquatic Invertebrates - Acute } 48 \mathrm{hr} \\
\text { EC50 mg/l }\end{array}$ & University of Hertfordshire (UK) & $2014-2015$ \\
\hline WFD & $\begin{array}{l}\text { Model-Based Prioritization Exercise- } \\
\text { supplementary data. Toxicity assessed by } \\
\text { PNEC with the corresponding AF } \\
\text { (QSARbased, Footprint, ETOC) }\end{array}$ & PNEC for freshwater & Publication, Daginnus et al. (2011) & 2011 \\
\hline
\end{tabular}

d) Data used/added to assess bioaccumulation

WFD

Model-Based Prioritization Exercise-

supplementary data. BCF values calculated by

EPI Suite TM v4.0 tool and from

Log (BCF) calculated by EPIsuite

Publication, Daginnus et al. (2011)

2011

WFD

QSAR. 


\section{e) Data used/added to assess endocrine disrupting effect}

EU-EDS database

Databank from the EU commission working on

the classification of endocrine disrupting

$$
\text { chemicals. }
$$

TEDX

The Endocrine Disruption Exchange.

Organization that focuses primarily on the

human health and environmental problems

caused by low-dose and/or ambient exposure
to endocrine disruptors. List of Potential

to endocrine disruptors. List of Potential

\section{Catg. 1 Evidence ED effect. Catg. STATE OF THE ART ASSESSMENT OF \\ ENDOCRINE DISRUPTERS \\ Final Report Project Contract Number \\ 070307/2009/550687/SER \\ 2 Potential ED. Catg. 3a No ED,}

Open source

ED potential on human and

environment according to

scientific evidence and

publications

2012

f) Data used/added - other

NORMAN

Exercise for prioritizing emerging substances

from the NORMAN network (network of

$x$ : yes

List of emerging substances

reference laboratories, research centres and

related organization for monitoring of emerging

environmental substances ) 


\section{Sources of experimental measured concentrations}

- Chiaia-Hernandez AC, Krauss M, Hollender J. (2013). Screening of lake sediments for emerging contaminants by liquid chromatography atmospheric pressure photoionization and electrospray ionization coupled to high resolution mass spectrometry. Environmental Science and Technology 47, 976-986. 180 pharmaceuticals, personal care products, pesticides, biocides, additives, corrosion inhibitors, musk fragrances, UV light stabilizers, and industrial chemicals were search in sediments from two sediment cores from the deepest part of Lake Greifensee.

- Müller A. (2016). Exploring temporal trends of pesticides in lake sediments by LC-HRMS. Masther Thesis. ETH-Eawag. A recent study of sediment concentrations in Lake Greifensee have showed that the following chemicals appear in at least 3 points above the limit of quantification: aldicarb-Na, atraton, 2-Octyl-2H-isothiazol-3-one (OIT), atrazine, chlortoluron, climbazol, cyproconazol, cyprodinil, difenoconazol, diuron, fenpropimorph, flusilazol, irgarol, isoproturon, mepanipyrim, N,N-Diethyl-meta-toluamide (DEET), penconazol, prochloraz, prometon, prometryn/terbutryn, propazin, propiconazol, pyrimethanil, tebuconazol, terbumeton, terbutylazin, dinoseb, fipronil-sulfid, fludioxonil, and triclosan.

- CIPEL specific campaign (2016). Preliminary results not yet publicly available have been used for the prioritization. The results contain 30 sampling points per substance including 7 PCBs, 8 PBDE, 18 pesticides (or residues from pesticides, 1 phthalate and $21 \mathrm{PAHs}$. The 95th percentile has been calculated for each substances and reported in the databank.

- Clara M, Gans O, Weiss S, Sanz-Escribano D, Scharf S, Scheffknecht C. (2009). Perfluorinated alkylated substances in the aquatic environment: An Austrian case study. Waterresearch 43, 4760-4768. Integration of the values for Lake Constance.

- Project "SCHTURM", Scheffknecht Christoph. Institut für Umwelt und Lebensmittelsicherheit des Landes Vorarlberg, Montfortstraße 4,6901 Bregenz.Umweltbundesamt GmbH and Environmental Institute of the State of Vorarlberg, Austria. Concentrations of PBDE and PFAS for Lake Constance and other alpine lakes from Austria.

- Botta F, Dulio V. (2014). Résultats de l'étude prospective 2012 sur les contaminants émergents dans les eaux de surface continentales de la métropole et des DOM. Rapport Final, DRC-13$136939-12927 \mathrm{~A}, 139 \mathrm{pp}$. A total of 134 substances have been searched in sediments from 158 sites located in the French territories, including reference and highly polluted sites.

- Vulliet E, Berlioz-Barbier A, Lafay F, Baudot R, Wiest L, Vauchez A, Lestremau F, Botta F, CrenOlivé C. (2014). A national reconnaissance for selected organic micropollutants in sediments on French territory. Environmental Science and Pollution Research 21, 11370-11379.

- Munoz G, Giraudel J-L, Botta F, Lestremau F, Dévier M-H, Budzinski H, Labadie P. (2015). Spatial distribution and partitioning behavior of selected poly- and perfluoroalkyl substances in freshwater ecosystems: A French nationwide survey. Science of the Total Environment 517, 4856. 115 river and 18 lake sampling sites has been investigated for 22 PFASs.

- McKnight et al. (2015). Sources, occurrence and predicted aquatic impact of legacy and contemporary pesticides in streams. Environmental Pollution 200,64-76. This study presents data on pesticide concentrations in sediments from four Danish river basins. A total of 44 substances were analyzed (18 herbicides, 11 fungicides and 15 insecticides).

- Schmid P. et al. (2010). Polychlorobiphényles (PCB) dans les eaux en Suisse : Données concernant la contamination des poissons et des eaux par les PCB et les dioxines. OFEV, numéro UW-1002-F, $107 \mathrm{p}$. Maximum sediment concentrations data in 21 study sites for i-PCBs and 8 study sites for dl-PCBs in Switzerland.

- Database of the Ecotox Centre for contaminant concentrations in sediment for Switzerland. Sediment concentrations for PAHs at 39 study sites from the cantons of VS, JU, GL and GE are also available. 


\section{Supporting information}

- Hlouskova V. et al. (2013). Brominated flame retardants and perfluoroalkyl substances in sediments. Science of the Total Environment 470-471, 407-416. This study reports results of analysis of various groups of halogenated chemicals, including brominated flame retardants (BFRs), such as polybrominated diphenyl ethers (PBDEs), hexabromocyclododecanes (HBCDs), tetrabromobisphenol A (TBBPA) and perfluoroalkyl substances (PFASs) in 31 sediment samples collected in different localities of the Czech Republic.

- Davidson C. et al. (2012). Contaminant residues and declines of the cascades frog in the Californian cascades. Environmental Toxicology and Chemistry, Vol. 31, No. 8, pp. 18951902. This study analyzed the sediment of 31 sample site in Californian cascades for 6 pesticides, 5 PCBs and 7 PAHs. The sediment detection frequency has also been determined.

- Schäfer R. B. et al. (2011). Effects of pesticides monitored with three sampling methods in 24 sites on macroinvertebrates and microorganisms. Environmental Science and Technology, 45, 1665-1672. Analyses of 97 pesticides in 24 southeast Australian stream sites over 5 months. 18 maximum concentrations in sediment available for 6 insecticides, 6 herbicides and 6 fungicides for 144 samples. 


\section{Equilibrium Partitioning approach for EQSsed derivation}

Calculation of EQSsed using the Equilibrium Partitioning approach (EqP).

The EqP approach postulates that chemical activity, which is essentially the freely dissolved-phase concentration in pore water, is an accurate predictor of bioavailability within an equilibrated aquatic system.

This approach was applied to translate the set of EQS proposals developed by the Ecotox Centre for surface waters into EQSsed using the following calculations:

$$
\begin{aligned}
E Q S_{\text {sed }, E q P, w w} & =\frac{K_{\text {sed-water }}}{R H O_{\text {sed }}} \times E Q S_{f w, e c o} \times 1000 \\
\text { CONVsed } & =\frac{R H O_{\text {sed }}}{\text { Fsolid }_{\text {sed }} \times R H O \text { solid }} \\
E Q S_{\text {sed }, E q P, d w} & =\text { CONVsed } \times E Q S_{\text {sed }, E q P, w w}
\end{aligned}
$$

\begin{tabular}{|c|c|c|c|}
\hline Parameter & Description & Unit & Default value \\
\hline$E Q S_{s e d, E q P, w w}$ & $\begin{array}{l}\text { Wet weight quality standard for sediment based } \\
\text { on equilibrium partitioning }\end{array}$ & $\mathrm{mg} \mathrm{kg}_{w w}{ }^{-1}$ & \\
\hline$K_{\text {sed-water }}$ & $\begin{array}{l}\text { Partition coefficient between sediment and } \\
\text { water }\end{array}$ & $\mathrm{m}^{3} \mathrm{~m}^{-3}$ & \\
\hline $\mathrm{RHO}_{\text {sed }}$ & Bulk density of wet sediment & $\mathrm{kg}_{w w} \mathrm{~m}^{-3}$ & 1300 \\
\hline \multicolumn{4}{|l|}{$E Q S_{f w, e c o}$} \\
\hline 1000 & Conversion factor from $\mathrm{m}^{3}$ to litre & $\mathrm{L} \mathrm{m}^{-3}$ & 1000 \\
\hline CONVsed & $\begin{array}{l}\text { Conversion factor for sediment concentration } \\
\text { wet-dry weight sediment }\end{array}$ & $\mathrm{kg}_{w w} \mathrm{~kg}_{\mathrm{dw}^{-1}}$ & \\
\hline Fsolid $_{\text {sed }}$ & Fraction solids in sediment & -- & 0.2 \\
\hline RHOsolid & Density of the solid phase & $\mathrm{kg}_{\text {solid }} \mathrm{m}_{\text {solid }}{ }^{-3}$ & 2500 \\
\hline$E Q S_{\text {sed,EqP,dw }}$ & $\begin{array}{l}\text { Dry weight quality standard for sediment based } \\
\text { on equilibrium partitioning }\end{array}$ & $m g \mathrm{~kg}_{\mathrm{dw}}{ }^{-1}$ & \\
\hline
\end{tabular}

Where: 